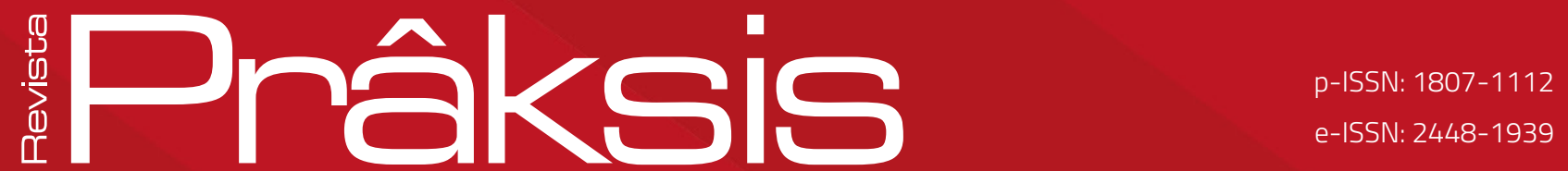

Recebido em: 01 de setembro de 2018 Aprovado em: 25 de fevereiro de 2019 Sistema de Avaliação: Double Blind Review RPR |a. 16 | n. 2 | p. 57-80 | mai./ago. 2019 DOI: https://doi.org/10.25112/rpr.v2i0.1766

\title{
DISPOSTAS E CORAJOSAS: MULHERES SUBVERSORAS DE NORMAS EM UM ESPAÇO DE APRENDIZAGEM DO MUAY THAI EM CAMAPUÃ/MS
}

\section{DISPLACED AND BOLDFUL: WOMEN SUBVERSING} STANDARDS IN A MUAY THAI LEARNING SPACE IN CAMAPUÃ/MS

\section{Marcelo Victor da Rosa}

Doutor em Educação pela Universidade Federal de Mato Grosso do Sul (Mato Grosso do Sul/Brasil). Professor na Universidade Federal de Mato Grosso do Sul (Mato Grosso do Sul/Brasil).

E-mail:marcelo.rosa@ufms.br.

\section{Andrey Monteiro Borges}

Mestre em Antropologia Social pela Universidade Federal de Mato Grosso do Sul (Mato Grosso do Sul/Brasil). E-mail: andreyedfisicaa@gmail.com.

\section{Fátima Espíndola Ferreira}

Graduada em Educação Física pela Universidade Federal de Mato Grosso do Sul (Mato Grosso do Sul/Brasil).

E-mail: fespindolaferreira@gmail.com. 


\section{RESUMO}

A Educação Física é uma área que possibilita espaço para discussões acerca das diferenças de gênero, preconceito, discriminação e sexualidade. Sabendo que a sociedade segue padrões e que, sujeitas a tais, algumas mulheres lutadoras são vigiadas e punidas tanto na educação formal quanto na informal, deste modo se faz importante investigar essa realidade. É neste sentido que essa pesquisa objetivou verificar os preconceitos relacionados à percepção de gênero e homossexualidade em 30 mulheres praticantes de Muay Thai. Essas responderam um questionário adaptado e estruturado com 19 questões. Segundo os dados, a presença de homossexuais na modalidade foi confirmada pelas interlocutoras, contudo, tal presença não foi o fator primordial para a existência de preconceitos às lutadoras, mas sim por serem mulheres. 0 fato de lutar ser associado à coragem contribui para que o preconceito em relação às lutadoras de Muay Thai seja menor se comparado a outros estudos de praticantes de diferentes modalidades esportivas. Consideramos que a mulher tem lutado em busca de reconhecimento e conquista de espaços, o que realça a necessidade de estudos sobre mulheres diretamente envolvidas no universo das Lutas, uma vez que gerar discussões é um meio de tensionar a nossa sociedade e aqui especificamente as instituições educacionais informais por sua história de conservadorismo, de desigualdade e de exclusões das diferenças.

Palavras-chave: Sexualidade. Mulheres. Gênero. Muay Thai. Educação.

\section{ABSTRACT}

Physical Education is an area that allows space for discussions about differences in gender, prejudice, discrimination and sexuality. Knowing that society follows standards and that, subject to such, some women fighters are watched and punished in both formal and informal education, so it is important to investigate this reality. It is in this sense that this research aimed to verify the prejudices related to the perception of gender and homosexuality in 30 women practicing Muay Thai. They answered an adapted and structured questionnaire with 19 questions. According to the data, the presence of homosexuals in the modality was confirmed by the interlocutors, however, such presence was not the main factor for the existence of preconceptions to the fighters, but because they were women. The fact that fighting is associated with courage contributes to the fact that the prejudice towards Muay Thai fighters is smaller compared to other studies of practitioners of different sports modalities. We consider that the woman has been fighting for recognition and conquest of spaces, which highlights the need for studies on women directly involved in the Fighting universe, since generating discussion is a means of stressing our society and specifically here educational institutions informal for their history of conservatism, inequality and exclusion from differences.

Keywords: Sexuality. Women. Genre. Muay Thai. Education. 


\section{INTRODUÇÃO}

Observa-se que a sociedade brasileira traz consigo uma resistência ao novo e ao diferente, essa resistência está relacionada ao preconceito e à falta de conhecimento. Quando as mulheres decidem ampliar seus horizontes buscando aprender técnicas de Lutas, especificamente o Muay Thai, torna-se necessário verificar a presença de ideias preconceituosas direcionadas a estas mulheres.

Sendo a Universidade um local de formação de professores/as e demais profissionais que irão contribuir na formação de outros/as cidadãos/ãs, torna-se necessária a abordagem de temas como "Mulher no Muay Thai e o preconceito", visto que grande parte da sociedade marginaliza aqueles/as que saem dos padrões ditos normais, estereotipando e discriminando, por exemplo, as mulheres lutadoras.

Mesmo a mulher batalhando em busca de espaço em meio a uma cultura machista, esta ainda é vista como sexo frágil e incapaz. Já a Educação Física por tratar da cultura de movimento, em volta das questões de inclusão, deve trabalhar este tema para que possa formar alunos/as com posicionamento aberto/reflexivo perante às diferenças.

[...] as modificações que ocorrem no corpo e também no comportamento das mulheres, em função da prática de atividades físicas, quando se diferenciam dos padrões culturalmente aceitos como normais, parecem ameaçar não apenas a superioridade masculina no campo destas práticas, mas as representações de ser homem e ser mulher (SILVANA GOELLNER, 2000, p. 91).

Embora ainda percebamos que determinadas modalidades de Luta são mais aceitas para homens do que para mulheres, os espaços de educação informal de Muay Thai são locais que potencializam a observação da prática desta arte marcial por parte deste público.

O tema aqui abordado é importante, pois, enquanto professores/a formadores/a de opinião, inseridos em uma sociedade que ainda interpreta os esportes de maneira sexista e, por vezes, rotula a mulher baseando-se em seu comportamento, seu corpo, sua maneira de vestir e andar, torna-se necessário verificar se há preconceitos direcionados às mulheres praticantes de Muay Thai.

Mediante ao exposto, surgiu o seguinte problema de pesquisa: Quais preconceitos estão relacionados à percepção de gênero e homossexualidade em mulheres praticantes de Muay Thai?

Diante de tal problemática, o objetivo desta pesquisa foi o de verificar preconceitos relacionados à percepção de gênero e homossexualidade em mulheres praticantes de Muay Thai. 


\section{A MULHER E O MUAY THAI}

\subsection{0 gênero aqui tem sido pensado como}

[...] condição social através da qual nós nos identificamos como masculinos e femininos. Não é algo natural que está dado, mas é construído social e culturalmente e envolve um conjunto de processos que vão marcando os sujeitos a partir daquilo que se identifica como masculino ou feminino (MÁRCIA FIGUEIRA et al., 2009, p. 10).

No que tange às diferenças relacionadas ao sexo, elas se dão a partir da ideia de que o homem é forte e a mulher é frágil, logo, considerando que existem homens fisicamente frágeis e mulheres fisicamente fortes, gênero deixa de ser visto com características masculinas e femininas, uma vez que tais performances são variáveis.

Dada a importância do que as pessoas pensarão de si, muitas mulheres ainda permanecem com seus desejos retraídos deixando assim de expressarem o que realmente pensam e acreditam, principalmente levando em consideração a ascendência descontrolada e muito bem instalada do conservadorismo em todas as camadas do poder político em nosso país. Mesmo com todo esse pânico moral evidente nos discursos e práticas políticas, as mulheres têm resistido e estão ocupando os espaços que ainda são majoritariamente de homens, como, por exemplo, nas lutas.

Conforme ressalta Adriana Piscitelli (2009), o acesso à educação foi fundamental para hoje termos mulheres nas escolas, nas universidades, atuando em diversas áreas. Convém aqui mencionar que, apesar de muita resistência, dependendo da posição social que ocupam essas mulheres, muitas das vezes elas ainda têm que conviver com o descontentamento por terem sua sexualidade colocada em dúvida.

O fato de uma mulher praticar alguma modalidade de luta, jogar futebol ou simplesmente não gostar de maquiagem, uma vez que estes são contrários aos padrões designados culturalmente em nossa sociedade como sendo feminino, torna-se motivo para que sua sexualidade seja questionada.

Tratando-se de modelo de sexualidade, Emerson Inácio (2002) ressalta que essa tem como padrão a heterossexualidade, o que não condiz com esta é considerado anormal, como, por exemplo, a homossexualidade. Considerar a homossexualidade como anormalidade é dar chancela à discriminação e preconceito, logo, a incompreensão ao que se vê como sendo anormal causa inércia e distancia as pessoas.

Nesse sentido, Adriana Nunan (2003, p. 59) afirma que: "O preconceito é visto como uma forma de construção do outro, a partir da própria neutralização desse outro. Implica a negação do indivíduo diferente e, no mesmo movimento, a afirmação da própria identidade como superior/dominante".

Para que o diferente seja aproximado das normas, há uma forma estratégica de conceituar algo que 
não se conhece, resultando em rotular o/a negro/a, a pessoa obesa, a mulher, o/a homossexual bem como todos/as aqueles/as que não cumprem com a normalidade estabelecida na sociedade de ser magro/a, homem, heterossexual e branco, como socialmente inferiores.

Dentre os sujeitos que são tidos como diferentes aqui citados, enfatizamos a mulher praticante de Muay Thai, pois segundo Phillip Lima e Sebastião Votre (2008), na Tailândia, país de origem da referida modalidade, houve um passado em que as mulheres não podiam assistir às lutas, pregavam que a presença delas traria má sorte aos lutadores.

De acordo com Dalton Castellano (2005), o Muay Thai é conhecido como Boxe Tailandês e teve sua origem na Tailândia a cerca de 2000 anos atrás. Já no Brasil, essa modalidade teve origem na década de 70.

Muitos vêem a modalidade como ainda sendo agressiva, mas se bem observarmos, notaremos que em todo tipo de esporte há agressividade, seja ela permitida ou não, o que os difere da luta é que nesta o/a aluno/a já espera tal agressão e traz consigo a técnica correta de se defender e são essas mesmas técnicas que muitas mulheres usam como uma forma de se defenderem de possíveis agressões em seu dia a dia.

A mulher foi por muito tempo vetada de muitas práticas, inclusive as esportivas e, embora ainda tenha que enfrentar discriminação e preconceito, a cada dia se supera, conquista seu espaço, possibilitando a quebra de tabus, mostrando para a sociedade que com resistência as mulheres ocupam diversos lugares.

Ainda que a prática esportiva feminina não seja novidade nestes tempos, as mulheres não se eximem de ampliar e diversificar sua participação em competições, apesar de constituírem um número bem menor se comparado aos homens (GOELLNER, 2000, p. 82).

A citação acima só vem afirmar o que ainda persiste no século XXI, as competições que contam com as participações das mulheres não têm a mesma divulgação e público quando comparada com as dos homens, tanto que nos eventos de lutas transmitidos pela mídia é rotineiro vermos de três a mais combates masculinos e apenas um feminino, ou ainda todos entre homens, mas dificilmente um evento onde as lutas sejam somente entre mulheres.

De acordo com Goellner (2000), o esforço físico, o excesso de suor, as fortes emoções, as competições seguidas da rivalidade consentida, assim como os músculos exaltados e a leveza das roupas, quando relacionadas à mulher, parece limitar a imagem ideal de feminilidade.

No entanto, há também aquelas mulheres que praticam o Muay Thai com a finalidade de aprender as técnicas da luta e participar de competições, estas talvez por se dedicarem mais tempo aos treinos, o corpo se torna forte e os músculos bem definidos, atingindo esse nível de aparência física ao qual a sociedade já não as vê como femininas e belas, mas sim como mulheres do corpo masculinizado. 


\section{ASPECTOS METOdOLÓGICOS}

Esta pesquisa é de cunho qualitativo, uma vez que busca a construção da realidade por meio de interpretações e embasamentos teóricos para com os dados de campo (GUNTHER, 2006).

A população alvo foi constituída por mulheres praticantes de Muay Thai, sendo estas calouras e veteranas, que frequentam uma academia localizada no município de Camapuã-MS. Ao todo foram entregues 40 questionários no período de janeiro a março de 2018, porém a amostra foi composta por 30 praticantes, pois as demais não devolveram o instrumento.

As informações foram obtidas por meio de um questionário estruturado com 19 questões fechadas, mistas e também questões abertas, com espaço para que as entrevistadas pudessem descrever seus relatos de situações vividas na prática do Muay Thai.

O questionário aplicado foi uma adaptação de Caroline Oliveira (2008). Este foi adaptado com a finalidade de absorver das lutadoras informações como idade; profissão; nível de escolaridade; tempo de prática do Muay Thai; ídolo; participação da família e amigos em relação a tal prática; interpretação das práticas corporais; possíveis preconceitos e discriminação relacionados à prática do Muay Thai e à sexualidade; também indagamos sobre percepção, envolvimento, interferência e influência de mulheres homossexuais durante a prática do Muay Thai.

A entrega dos questionários, assim como sua devolução, foi feita pessoalmente na própria academia em dias de aulas. No ato da entrega foi esclarecido que as identidades das interlocutoras seriam protegidas de forma a seguir as normas éticas da pesquisa.

Após recolhidos, os questionários foram numerados de 1 a 30. Como forma de nomear sem que suas identidades fossem reveladas, utilizou-se a letra "L", de lutadora, seguida do número correspondente.

Para organização dos resultados foi feito análise de conteúdo e a partir de quadros e citações de alguns relatos que contribuíam para um melhor análise e entendimento do/a leitor/a. De acordo com Rita Caregnato e Regina Mutti (2006, p. 682), “[...] na análise de conteúdo o texto é um meio de expressão do sujeito, onde o/a analista busca categorizar as unidades de texto (palavras ou frases) que se repetem, inferindo uma expressão que as representem".

As questões foram lidas e analisadas uma a uma, com a finalidade de entender, registrar e organizar os dados para que chegássemos à identificação das unidades de significados. Essas unidades de significados são as palavras/conceitos que se repetiam ao longo das respostas das mulheres praticantes de Muay Thai na mesma questão do questionário. Vale ressaltar que os discursos das lutadoras foram escritos na íntegra, não sendo feitas correções quanto à linguagem formal. 
Feito isso, os dados foram organizados em forma de quadros, bem como selecionamos alguns relatos das mulheres lutadoras que contribuíram para uma melhor análise, sendo assim, essa foi feita a partir dos relatos de experiências pessoais das interlocutoras, dialogando principalmente com a literatura de gênero e sexualidade.

\section{ANÁLISE DE DADOS}

\subsection{AS LUTADORAS}

A média de idade das entrevistadas foi de 32 anos e 8 meses, sendo 20 anos a menor idade e 46 a maior idade. Todas as lutadoras possuíam maioridade.

Com relação à profissão, a predominante foi a de professora, mas vale ressaltar que as praticantes de Muay Thai desenvolvem variadas atividades profissionais, como se pode observar no quadro 1.

\section{Quadro 1 - Quadro de profissões}

\begin{tabular}{|l|l|}
\hline Profissões & Quantidade \\
\hline Professora & 05 \\
\hline Servidora pública & 04 \\
\hline Bancária & 02 \\
\hline Manicure & 02 \\
\hline Advogada & 02 \\
\hline Autônoma & 02 \\
\hline Vigia & 01 \\
\hline Serviço geral & 01 \\
\hline Dona de casa & 01 \\
\hline Profissões & Quantidade \\
\hline
\end{tabular}




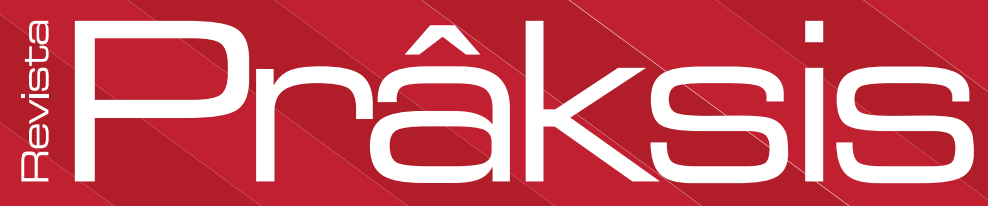

\begin{tabular}{|l|l|}
\hline Costureira & 01 \\
\hline Consultora de vendas & 01 \\
\hline Serralheira & 01 \\
\hline Cabeleireira & 01 \\
\hline Arquiteta & 01 \\
\hline Esteticista & 01 \\
\hline Atendente & 01 \\
\hline Técnica em enfermagem & 01 \\
\hline Bacharel em direito & 01 \\
\hline Juíza de paz & 01 \\
\hline
\end{tabular}

Os dados expostos no quadro 1 corroboram o observado por Claúdia Vianna (2013, p. 166): "Mais de $70 \%$ das mulheres ativas no mercado de trabalho continuam empregadas em profissões consideradas femininas, comoéocaso dasfonoaudiólogas, nutricionistas, biblioteconomistas, cozinheiraseprofessoras".

Mesmo a mulher conquistando seu espaço, exercendo profissões socialmente consideradas próprias para homens, podemos ponderar que algumas funções são designadas para as mulheres, não por sua capacidade de modo geral, mas sim por estereótipos construídos ao longo da história da humanidade (TALITA OLIVEIRA, 2013).

Buscamos saber qual era o nivel de escolaridade das lutadoras, concluímos, então, que a maioria possui ensino superior completo. 


\section{Quadro 2 - Nível de escolaridade}

\begin{tabular}{|l|l|}
\hline Nível de Escolaridade & Quantidade \\
\hline Superior Completo & 18 \\
\hline Ensino Médio Completo & 07 \\
\hline Superior Incompleto & 04 \\
\hline Ensino Médio Incompleto & 01 \\
\hline
\end{tabular}

Com relação a qual curso fez ou está fazendo no Ensino Superior, dentre as 18 alunas que disseram ter Ensino Superior Completo, uma não relatou qual curso. Apenas 04 estão a caminho de sua primeira graduação.

\section{Quadro 3 - Áreas acadêmicas}

\begin{tabular}{|l|l|l|l|}
\hline \multicolumn{2}{|l|}{ Superior Completo } & Superior Incompleto \\
\hline Áreas & Quantidade & Áreas & Quantidade \\
\hline Direito & 05 & Licenciatura em Educação Física & 02 \\
\hline Assistência Social & 02 & Administração & 01 \\
\hline Letras & 02 & Farmácia & 01 \\
\hline Pedagogia & 02 & & \\
\hline Educação Física & 01 & & \\
\hline Licenciatura em Biologia & 01 & & \\
\hline Arquitetura & 01 & & \\
\hline Estética e Cosmética & 01 & & \\
\hline
\end{tabular}




\begin{tabular}{|l|l|l|l|}
\hline \multicolumn{2}{|l|}{ Superior Completo } & Superior Incompleto \\
\hline Áreas & Quantidade & Áreas & Quantidade \\
\hline Pedagogia em Educação Infantil & 01 & & \\
\hline Administração em Agronegócio & 01 & & \\
\hline
\end{tabular}

É nesse sentido que concordamos com Oliveira quando ressalta que:

Além de serem sexualmente demarcados, alguns setores ocupacionais seguem reproduzindo em seu interior uma divisão das tarefas relacionadas às características biológicas de homens e mulheres e às qualidades que thes são atribuídas social e culturalmente (2013, p. 154).

Outra informação obtida foi saber a quanto tempo as lutadoras praticavam Muay Thai. A maioria disse praticar a referida modalidade há menos de 1 ano, isso mostra que as mulheres são iniciantes.

\section{Quadro 4 - Tempo de Prática do Muay Thai}

\begin{tabular}{|l|l|}
\hline Tempo de Prática & Quantidade \\
\hline Menos de 1 ano & 24 \\
\hline A mais de 5 anos & 02 \\
\hline 3 anos & 02 \\
\hline 2 anos & 01 \\
\hline 1 ano & 01 \\
\hline
\end{tabular}


Buscamos saber quais referências/ídolos as lutadoras tinham nas Lutas, sendo esses:

Quadro 5 - Ídolos citados

\begin{tabular}{|l|l|}
\hline İdolo & Quantidade \\
\hline Deixaram de responder & 08 \\
\hline Relataram não ter ídolo & 08 \\
\hline Meu professor Vinícius "Martelo" & 05 \\
\hline Meu professor Enéas & 02 \\
\hline Anderson Silva & 02 \\
\hline Cristiane "Cyborg" & 02 \\
\hline Honda Rousey & 02 \\
\hline José Aldo & 01 \\
\hline Júnior Cigano & 01 \\
\hline Eduardo Maiorini & 01 \\
\hline
\end{tabular}

Somando as que deixaram de responder com as que relataram não ter ídolo, estas compõem a maioria das respostas. Sete praticantes têm como ídolo os seus próprios professores, o que se justifica pelo fato de 24 delas estarem vivenciando e ainda conhecendo a modalidade a menos de 1 ano.

Algumas lutadoras apontaram mais de um ídolo, e os citados são majoritariamente homens, ficando aqui evidente que para esse grupo de mulheres no Muay Thai, mesmo havendo lutadoras que estão em destaque na cena mundial sendo noticiadas com mais frequência, ainda assim as alunas aqui entrevistadas pouco citam referências de mulheres.

Nesse caso, os dados fortalecem a ideia do que rotineiramente ocorre em outras determinadas modalidades esportivas, na qual a maioria dos praticantes são homens e as disputas entre mulheres são divulgadas em menor escala. Esse fato contribui para que tenhamos poucas mulheres como referência 
no mundo das Lutas, bem como outros fatores associados a uma feminilidade inferiorizada pelo universo esportivo.

Cláudio Nunes (2004) observou três academias de lutas e verificou que nesses espaços não havia o envolvimento direto de mulheres nas aulas e competições. Ele ainda salienta que, "as práticas de MMA são desenvolvidas preferencialmente entre jovens e adultos brancos do sexo masculino" (idem, 2004, p. 108).

Também foi questionado como é a participação da família e amigos das respondentes em relação à prática do Muay Thai.

\section{Quadro 6 - Participação da Família e Amigos}

\begin{tabular}{|l|l|}
\hline Participação & Quantidade \\
\hline Dão total incentivo & 27 \\
\hline São contra, mas permitem & 01 \\
\hline Indiferente & 01 \\
\hline Não conseguiu avaliar & 01 \\
\hline
\end{tabular}

A maioria tem o apoio e o incentivo da família e amigos, sendo que apenas uma não tem esse apoio, mas pratica mesmo assim. Convém ressaltar que a aprovação familiar, assim como o estímulo daqueles que as cercam, nesse caso os/as amigos/as, muito contribui para a aprendizagem. De acordo com Oliveira (2008, p. 30), "O incentivo da família é importante no desenvolvimento de qualquer prática esportiva e quando se trata de uma modalidade em que as práticas são vistas de maneira diferente pela sociedade, seu papel se torna de apoio ou barreira [...]".

Luiz Vilani e Dietmar Samulski, ao fazerem uma revisão sobre a influência dos pais na carreira esportiva de crianças e adolescentes, observaram que "[...] a carreira bem-sucedida do atleta muitas vezes pode ser creditada aos familiares pelo encorajamento, aquisição de valores [...] e suporte necessário durante a carreira [...]" (idem, 2002, p. 1).

Em outra questão, com a finalidade de identificar como as lutadoras interpretam as práticas corporais, foi sugerido que as mesmas relacionassem tais práticas como sendo de homem, mulher ou ambos. 


\section{Quadro 7 - Interpretação das Práticas Corporais}

\begin{tabular}{|l|l|l|l|}
\hline Modalidade & Ambos & Mulher & Homem \\
\hline Muay Thai & 28 & 01 & 01 \\
\hline Voleibol & 28 & 02 & \\
\hline Natação & 28 & 02 & \\
\hline Dança & 28 & 02 & \\
\hline Caminhada & 28 & 02 & \\
\hline Lutas & 27 & 02 & 01 \\
\hline Futebol & 27 & 01 & 02 \\
\hline Musculação & 27 & 02 & 01 \\
\hline Basquetebol & 27 & 01 & 02 \\
\hline Ginástica artística & 26 & 04 & \\
\hline Ginástica rítmica & 26 & 04 & \\
\hline Ginástica (fitness) & 25 & 05 & \\
\hline Hidroginástica & 25 & 04 & 01 \\
\hline
\end{tabular}

Foi possível identificar que, a maioria das entrevistadas considera as práticas corporais como sendo para ambos, o que é muito potente no campo das Lutas, mas ainda há quem considere que Muay Thai, futebol, basquetebol, musculação, hidroginástica e Lutas sejam praticadas somente por homens e a dança assim como a ginástica sejam praticadas somente para mulheres, pois, como afirma Oliveira (2008, p. 32): "No futebol, o corpo da mulher é encarado como um corpo feminino em uma prática masculina, assim como na dança e na ginástica existe essa 'comparação' em relação à participação masculina".

Quando questionadas se ainda existe preconceito por parte da sociedade em relação às mulheres que praticam Muay Thai, 21 delas responderam que não e 09 responderam sim. Diante disso, procuramos 
saber das lutadoras se houveram situações em que foram discriminadas pelo fato de praticarem Muay Thai. Nesta, 28 responderam não terem passado por nenhuma situação de discriminação e 02 relataram já terem sofrido. Acreditamos que o fato de 28 alunas não terem passado por nenhuma situação de discriminação/preconceito foi preponderante para que 21 mulheres não visualizassem o preconceito ao qual 9 de suas colegas dizem ter passado.

Segundo a L13 e L28, que responderam não terem sido discriminadas, elas foram inclusive elogiadas por estarem praticando Muay Thai.

"[...] recebi muitos elogios por estar praticando Muay Thai" (L13).

"[...] todos acham que sou muito disposta e corajosa" (L28).

Por outro lado, as duas mulheres que relataram situações discriminatórias, foi possível observar a presença de misoginia na qual a mulher tem uma característica, um lugar específico, limitado. De acordo com Victor Menezes (2013), a misoginia se caracteriza pelo desprezo ou ódio às mulheres.

"Uma vez quando fui procurar como fazer para começar a treinar Muay Thai, o professor, olhou e disse: Não gosto de dar aula para mulher" (L1).

"Falam que mulher não aguenta porrada, que mulher tem que ficar em casa lavando, cozinhando e passando, a mesma ladainha de sempre" (L8).

Ao apresentarem atitudes e procedimentos que possam contribuir para que todas as pessoas se sintam acolhidas nos espaços onde há atividades físicas e de lazer, Figueira et al. (2009) consideram que, quando nos comprometemos com as questões ligadas à discriminação de gênero, estamos contribuindo para que os estereótipos sejam identificados, denunciados e desqualificados.

Com a intenção de buscar o discurso das interlocutoras acerca da sexualidade, perguntamos se conhecem alguma mulher homossexual que pratica Muay Thai, 27 responderam que sim e 03 disseram não conhecer.

Diante disso, procuramos saber se as lutadoras já haviam sido identificadas como homossexuais pelo simples fato de praticarem Muay Thai, 28 disseram não ter passado por nenhuma situação e 02 afirmaram não se lembrarem de algum ocorrido.

Ao buscar saber se o Muay Thai influenciou na orientação sexual das lutadoras, todas afirmaram não haver influenciado. Além disso, perguntamos se o Muay Thai poderia influenciar na orientação sexual de alguma mulher, as 30 lutadoras disseram que não, e as suas justificativas foram agrupadas em unidades de significados apresentadas no quadro a seguir: 


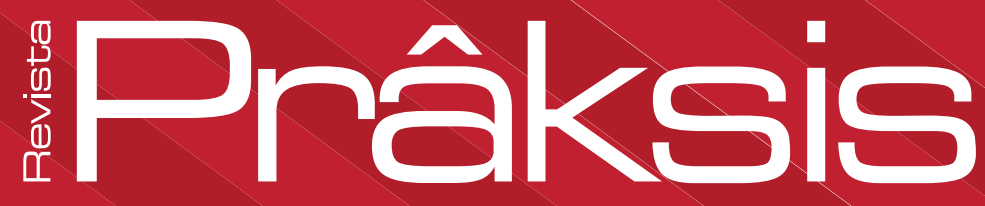

\section{Quadro 8 - Relação entre sexualidade e Lutas}

\begin{tabular}{|l|l|}
\hline Núcleos & Quantidade \\
\hline Determinismo Biológico & 04 \\
\hline Contradição & 02 \\
\hline Cuidar de si Mesma & 02 \\
\hline Auto Estima & 01 \\
\hline Confusão Conceitual & 01 \\
\hline Defesa Pessoal & 01 \\
\hline Determinismo Social & 01 \\
\hline Estereótipo & 01 \\
\hline Liberdade & 01 \\
\hline Sexualidade Fixa & 01 \\
\hline Superar Limites & 01 \\
\hline
\end{tabular}

De acordo com a L3, "um esporte em nada interfere na orientação sexual de uma pessoa. Orientação sexual é algo orgânico, da pessoa, sua natureza e não do meio (prática de esporte)".

"De forma geral penso eu que o Muay Thai não influencia na orientação sexual porque o esporte em geral, independente do gênero, não induz ninguém a sentir atração por uma pessoa do mesmo sexo, acredito que isso é de nascença" (L16).

"A sexualidade humana é um tema que gera polêmica e muitas controvérsias, uma vez que envolve questões afetivas, papéis esperados e desempenhados em uma sociedade e também comportamentos" (L16).

Segundo a L5, "se fosse assim, todas nós que praticamos o esporte, seríamos obrigadas a mudar nossa orientação sexual".

L9: "Acho que cada um sabe o que quer na vida, pois não será um esporte que vai mudar ou influenciar". 
L23: "O Muay Thai é um esporte como qualquer outro, servindo inclusive como defesa pessoal, jamais irá influenciar na orientação sexual de quem quer que seja".

Observamos que o determinismo biológico foi a unidade de significado mais presente nos discursos das lutadoras quando questionadas se o Muay Thai poderia influenciar na orientação sexual de uma mulher, de acordo com os discursos, o ser humano já nasce com sua orientação sexual, visto que esta é algo orgânico e não adquirida por meio de práticas esportivas.

O fato de uma pessoa praticar alguma Arte Marcial, jogar futebol ou qualquer outro esporte, não será fator decisivo para que ela se torne ou não homossexual. Guacira Louro afirma:

\begin{abstract}
A aceitação da existência de uma matriz biológica, de algum atributo ou impulso comum que se constitui na origem da sexualidade humana persiste em algumas teorias. Quando isso ocorre, opera-se com uma noção universal e trans-histórica da sexualidade e, muitas vezes, remete-se ao determinismo biológico (2007, p. 209).
\end{abstract}

Somos formados/as, constituídos por uma sociedade que é sexista, contudo, cada sujeito em sua individualidade vai se subjetivando e vivendo sua sexualidade. Desta forma, o esporte, a educação e a família, por exemplo, atuam em nossa sexualidade, mas não determinam.

Enfatizamos aqui a escola enquanto uma instituição na qual abarca sujeitos com diferentes marcas sociais, porém, historicamente, vêm colocando à margem/exclusão tais atores sociais (alunos/as, professores/as, técnicos/as e comunidade). Dito isso, nosso projeto de educação/escola prioriza/valoriza a pluralidade de vivências, existências e práticas sociais, se contrapondo politicamente à concepção escola sem partido, uma vez que essa interdita as possibilidades de trabalhos pedagógicos que almejam a diversidade/inclusão, silenciando principalmente os/as professores/as.

Outro ponto discutido foi se as mulheres homossexuais são as que mais praticam o Muay Thai, 28 disseram não serem as homossexuais as mais envolvidas com essa Luta e 02 disseram serem estas as que mais participam. 


\section{Quadro 9 - Muay Thai e homossexualidade}

\begin{tabular}{|l|l|}
\hline Núcleos & Quantidade \\
\hline Saúde & 05 \\
\hline Heterossexualidade & 04 \\
\hline Igualdade & 03 \\
\hline Estética & 02 \\
\hline Gosto & 02 \\
\hline Identidade de Gênero & 02 \\
\hline Amor & 01 \\
\hline Artes Marciais & 01 \\
\hline
\end{tabular}

A L1 afirma que, "na academia onde treino, a maioria das mulheres são casadas com homens".

Para a L8, "o Muay Thai é aberto para todos que gostam da Arte Marcial".

L23 esclarece que "o Muay Thai é um esporte como qualquer outro, mas possui um diferencial que atrai muitas mulheres, pois além de servir como defesa pessoal ainda ajuda na perda de peso".

Apesar de ainda existirem pessoas que classificam o Muay Thai como sendo um esporte masculinizado, a L1 confirma que a maioria das praticantes da modalidade do grupo estudado são heterossexuais e, como destaca a L8, é uma Arte para todas que gostam de praticá-la.

Embora alguns discursos apontem para a heterossexualidade, é importante considerar que o fato de uma pessoa ser casada com outra do gênero oposto não é assertiva suficiente para definí-la como sendo heterossexual, como, por exemplo, o desejo e prática sexual de mulheres que são casadas com homens e procuram outras mulheres para satisfazerem suas lubricidades.

Nesse sentido, Judith Butler (2003, p. 176) ressalta que "[...] há estruturas de homossexualidade psíquica no âmbito das relações heterossexuais e estruturas de heterossexualidade psíquica no âmbito da sexualidade e dos relacionamentos lésbicos e gays".

Ao analisar as falas das jogadoras de futsal, Oliveira (2008) diz que estas também afirmaram não serem as mulheres homossexuais as que mais se envolvem com o futsal feminino. Os resultados de sua 
pesquisa mostraram que "[...] ser homossexual é uma consequência não da prática do esporte, mas da própria condição da mulher que se assume homossexual e coincidentemente gosta de futsal, portanto não se pode generalizar" (idem, 2008, p. 42).

Outro ponto questionado foi saber como as lutadoras se sentiam praticando Muay Thai com mulheres homossexuais. Das 30 interlocutoras, 28 responderam se sentir bem e 02 omitiram tal resposta. Nas justificativas, o respeito, igualdade e caráter foram por vezes mencionados.

\section{Quadro 10 - Convívio com homossexuais}

\begin{tabular}{|l|l|}
\hline Núcleos & Quantidade \\
\hline Respeito & 06 \\
\hline Igualdade & 04 \\
\hline Indiferente & 03 \\
\hline Caráter & 02 \\
\hline Amizade & 01 \\
\hline Companheirismo & 01 \\
\hline Prática Esportiva & 01 \\
\hline Troca de Conhecimento & 01 \\
\hline Não Julgamento & 01 \\
\hline Não Tenho Preconceito & 01 \\
\hline
\end{tabular}

L8: "[...] elas me tratam muito bem, e o melhor, me respeitam".

L15: "[...] sou evangélica, mas respeito as diferenças. Estar no mesmo ambiente que as homossexuais não me incomoda, apenas respeito para ser respeitada".

L5: "[...] são pessoas iguais a todas as demais, isso não muda o caráter delas, eu acho que o que conta é isso".

Diante das considerações expressas pelas interlocutoras, faz-se necessário repensar o discurso acerca do respeito, pois, conforme Rossi, 
[...] a busca pelo respeito se dá a partir da idéia de que existe um comportamento hegemônico que determina o que é ser "normal" em contraponto do que é ser "anormal", e as diferenças desses grupos seriam negadas pela diferença de uma identidade hegemônica (2008, p. 4).

Desta forma, o respeito revela uma hierarquia nas relações entre os sujeitos diferentes, e lembramos que toda hierarquia estabelece relações de poder, onde, neste contexto, um é superior e outro é inferior, não contribuindo para um olhar de alteridade, a qual a diferença não resulte em exclusões.

Com a finalidade de verificar se as lutadoras percebiam homossexuais no local onde praticam Muay Thai, essa percepção foi então questionada; 24 afirmaram reconhecer tais presenças e 06 disseram não notar. Todas as 24 afirmaram não haver interferência.

Quadro 11 - Homossexualidade no contexto da prática do Muay Thai

\begin{tabular}{|l|l|}
\hline Núcleos & Quantidade \\
\hline Igualdade & 05 \\
\hline Respeito & 04 \\
\hline Indiferente & 04 \\
\hline Amizade & 02 \\
\hline Normalidade & 02 \\
\hline Caráter & 01 \\
\hline Cuidar de si Mesma & 01 \\
\hline Disciplina & 01 \\
\hline Escolhas & 01 \\
\hline Liberdade & 01 \\
\hline Preconceito & 01 \\
\hline
\end{tabular}


A L1 defende que, "[...] mesmo uma colega que gosta de outra mulher, isso não vai mudar em nada o meu respeito por ela".

"Elas me tratam com todo respeito, não se importando com o tipo de vida que tenho, por isso não vejo o porquê de tratá-las de maneira diferente" (L5).

"Minha opinião não vai mudar o mundo" (L8).

Partindo do fato das interlocutoras perceberem mulheres homossexuais praticando Muay Thai, convém salientar que, de acordo com a maioria das alunas, tal situação não interfere em sua relação com as mesmas, pois consideram que homossexuais ou heterossexuais, apesar de expressarem diferenças no campo da sexualidade, devem ter seus direitos resguardados enquanto sujeitos políticos.

Uma última questão foi elaborada perguntando se havia algo sobre essa temática que as entrevistadas gostariam de expressar que ainda não tinha sido exposto, 18 responderam que não e 12 responderam sim.

As unidades de significado presentes nestes últimos relatos, com exceção de convivência, julgamento e determinação foram praticamente as mesmas presentes no quadro 12 , como podemos verificar abaixo:

\section{Quadro 12 - Últimos relatos}

\begin{tabular}{|l|l|}
\hline Núcleos & Quantidade \\
\hline Convivência & 01 \\
\hline Cuidar de si Mesma & 01 \\
\hline Determinação & 01 \\
\hline Direito & 01 \\
\hline Escolha & 01 \\
\hline Estética & 01 \\
\hline Identidade Sexual & 01 \\
\hline Igualdade & 01 \\
\hline Julgamento & 01 \\
\hline
\end{tabular}




\begin{tabular}{|l|l|}
\hline Núcleos & Quantidade \\
\hline Respeito & 01 \\
\hline Saúde & 01 \\
\hline
\end{tabular}

L30: "[...] não podemos julgar as pessoas pela sua sexualidade e sim pelas suas atitudes".

"O Muay Thai é um esporte maravilhoso para nós mulheres, porque, além de definir o corpo, ele ajuda a diminuir o stress, além de muitos outros benefícios que traz para a saúde" (L13).

"A mulher quando invade o mundo dito masculino em qualquer área de serviço ou esporte, esta é taxada de sapatão ou machorra, somos taxadas de sexo frágil, mas somos guerreiras, fortes e iremos chegar onde queremos, nem nada e nem ninguém vai conseguir nos parar" (L1).

Para tanto, Felipe Almeida et al. (2008), salientam que o fato de, durante as aulas, uma mulher enfrentar um homem pode contribuir para que as diferenças socialmente construídas entre as identidades de gênero sejam problematizadas, tensionando assim os limites da fragilidade feminina.

O discurso da L13 condiz com a unidades de significado presentes no quadro 10 (saúde e estética), e reafirma que estas buscam o Muay Thai não com finalidade de competição, mas sim por melhoria para a saúde. Em relação ao discurso da L1, esta afirma que as mulheres, ao frequentarem espaços dominados por homens, passam então a serem discriminadas, entretanto, essas alunas continuam a resistir nestes espaços.

\section{CONSIDERAÇÕES FINAIS}

A sexualidade é orgânica e o Muay Thai, neste estudo, não pode ser entendido como sendo um esporte para homens, mas sim para todos/as. Para as mulheres lutadoras de Camapuã/MS que participaram desta investigação, a finalidade de aquisição de técnica de defesa pessoal e saúde faz com que a convivência entre as diferenças ocorra no contexto investigado.

Conviver, nesse sentido, para as lutadoras, perpassa questões relacionadas ao respeito, contudo, alguns/as autores/as aqui citados/as criticam o uso do enunciado de respeito, por entenderem que esse camufla os sistemas hierárquicos que formam binarismos e mantém os diferentes como inferiores, porém próximos e vigiados.

Aproximando este estudo com o de Maria Ribeiro (2018), Oliveira (2008) e Lovisi et al. (2018), observase que o preconceito em relação às lutadoras de Muay Thai é menor se comparado às jogadoras de futebol 
e/ou atletas de levantamento de peso. Ao identificar preconceitos sofridos por mulheres praticantes de futebol, Ribeiro (2018, p. 17) afirma que: "[...] as mulheres que jogam futebol ainda passam pelo constrangimento de ter sua sexualidade questionada e julgada de maneira errônea".

Nesse contexto, Oliveira (2008) enfatiza que no futebol/futsal, a orientação sexual das jogadoras é constantemente indagada, e os atos discriminatórios partem dos homens, das meninas de outras modalidades e até mesmo da própria família, pois generalizam e rotulam como sendo homossexuais as mulheres que jogam futebol.

Ayra Lovisi et al. (2018), ao analisarem a abjeção dos corpos de mulheres atletas do levantamento de peso, observaram que a força e a potência muscular elevada são marcas de seus corpos atléticos que colocam suas sexualidades em jogo.

A partir da percepção desse grupo de 30 mulheres, essas identificam a presença de homossexuais na prática do Muay Thai, visto que a maioria das interlocutoras respondeu notar esse público, no entanto, não são elas as que mais se envolvem com a referida modalidade de Luta.

Sobre o preconceito no contexto estudado, este acontece por meio de estereótipos e misoginias, e partem de alguns homens que as desprezam somente pelo fato de serem mulheres, as vêem como sexo frágil, afirmando que lugar de mulher é em casa, passando e cozinhando, e não em espaços educacionais de Lutas.

De acordo com Berta Cardoso et al. (2015), conhecer a realidade das alunas praticantes de Lutas pode ser um meio de superar os estereótipos em relação à participação das mulheres nas modalidades de Lutas, estereótipos estes que ainda estão presentes na sociedade contemporânea.

Conviver e, consequentemente, conhecer a capacidade das alunas praticantes de Lutas poderá contribuir para a compreensão de que não existe local, trabalho ou esporte específico para a mulher, pois esta não é objeto manipulável, mas sim um sujeito político que tem se apropriado de espaços públicos e privados, discutindo pautas e lutando por direitos por meio de movimentos sociais, como, por exemplo, o movimento Feminista.

\section{REFERÊNCIAS}

ALMEIDA, Felipe Quintão; MORAES, Claúdia Emília Aguiar; THOMAZINI, Samuel Oliveira. Controle de si, Dor e Representação Feminina Entre Lutadores (as) de Mixed Martial Arts. Revista Pensar a Prática, Goiás, v. 11, n. 3, 2008. 
BUTLER, Judith. Problemas de Gênero: Feminismo e Subversão da Identidade. Rio de Janeiro: Civilização Brasileira, 2003.

CARDOSO, Berta Leni Costa; SAMPAIO, Tânia Mara Vieira; SANTOS Doiara Silva dos. Dimensões Socioculturais do Boxe: Percepção e Trajetória de Mulheres Atletas. Revista Movimento. Rio Grande do Sul, v. 21, n. 1, p. 139-153, 2015.

CAREGNATO, Rita Catalina Aquino e MUTTI, Regina. Pesquisa qualitativa: análise de discursos versus análise de conteúdo. Texto Contexto Enferm. Florianópolis, out./dez, n. 15, a. 4, p. 679-84, 2006.

CASTELLANO, Dalton. Guia Prático de Defesa Pessoal: Muay Thai. São Paulo: Escala, 2005.

FIGUEIRA, Márcia Luiza Machado; GOELLNER, Silvana Vilodre; MOURÃO, Ludmila; VOTRE, Sebastião Josué. Gênero e raça: inclusão no esporte e lazer. Porto Alegre: Ministério do Esporte, 2009.

GOELLNER, Silvana Vilodre. Mulheres em Movimento: Imagens Femininas na Revista Educação Physica. Educação \& Realidade. Porto Alegre, jul./dez. 2000.

GUNTHER, Hartmut. Pesquisa Qualitativa Versus Pesquisa Quantitativa: Esta Ė a Questão? Psicologia: Teoria e Pesquisa, Brasília, v. 22, n. 2, p. 201-210, mai./ago. 2006.

INÁCIO, Emerson da Cruz. Homossexualidade, homoerotismo e homossociabilidade: em torno de três conceitos e um exemplo. In: GARCIA, Wilton; SANTOS, Rick. (Org). A escrita de adé: perspectivas teóricas dos estudos gays e lésbic@s no Brasil. São Paulo: Xamã: NCC/SUNY, 2002.

LIMA, Phillip Barbosa Barreto; VOTRE, Sebastião Josué. Representação de gênero para praticantes de Muay Thai do Rio de Janeiro. Fazendo Gênero, Florianópolis 25 a 28/08, 2008.

LOURO, Guacira Lopes. Gênero, sexualidade e educação: Das afinidades políticas às tensões teóricometodológicas. Educação em Revista, Belo Horizonte, v. 46, n. 46, p. 201-218, dez. 2007.

LOVISI, Ayra; MOURÃO, Ludmila; NOVAIS, Mariana; SOARES, João Paulo Fernandes. Performatividades de Gênero e a Abjeção dos Corpos de Mulheres no Levantamento de Peso. Revista Movimento, Porto Alegre, v. 24 n. 1, p. 107-118, jan./mar. 2018.

MENEZES, Victor Henrique da Silva. Ciudad Juárez: a cidade do silêncio. História e História, Campinas, v. 1, n. 1, mai. 2013. 
NUNAN, Adriana. Homossexualidade: do preconceito aos padrões de consumo. Rio de Janeiro: Caravansarai, 2003.

NUNES, Cláudio Ricardo Freitas. Corpos na Arena: Um Olhar Etnográfico Sobre as Práticas das Artes Marciais Combinadas. Dissertação (Mestrado em Ciências do Movimento Humano) - UFRG, Porto Alegre, 2004.

OLIVEIRA, Caroline Silva de. Mulheres em quadra: o futsal feminino fora do armário. Trabalho de Conclusão de Curso (Graduação em Educação Física) - Universidade Federal de Mato Grosso do Sul, Campo Grande, 2008.

OLIVEIRA, Talita Santos de. A Inserção das Mulheres na Construção: Um retrato midiático sobre a expressão e reprodução da feminilidade no setor. In: Yannoulas, Silvia Cristina. Trabalhadoras: Análise da Feminilização das Profissões e Ocupações, Brasília: Aboré, 2013.

PISCITELLI, Adriana. Gênero: a história de um conceito. In Coleção sociedade em foco: Introdução às ciências sociais. São Paulo: Berlendis, p. 118-146, 2009.

RIBEIRO, Maria Elizia de Melo e ROSA, Marcelo Victor da. 0 Preconceito Sofrido Para com as Mulheres que Praticam Futebol. Trabalho de Conclusão de Curso (Graduação em Educação Física) - Universidade Federal de Mato Grosso do Sul, Camapuã, 2018.

ROSSI, Alexandre José. Políticas para homossexuais: uma breve análise do programa Brasil sem homofobia e do tema transversal orientação sexual. Fazendo Gênero 8: Corpo, Violência e Poder, Florianópolis, 2008.

VIANNA, Cláudia Pereira. A feminilização do Magistério na Educação Básica e os Desafios Para a Prática e a Identidade Coletiva Docente. In: Yannoulas, Silvia Cristina. Trabalhadoras: Análise da Feminização das Profissões e Ocupações. Brasília: Aboré, 2013.

VILANI, Luiz Henrique Porto; SAMULSKI, Dietmar Martins. Família e Esporte: uma revisão sobre a influência dos pais na carreira esportiva de crianças e adolescentes. In: Silame Garcia, Emerson e Lemos, Kátia Lúcia Moreira. Temas atuais VII: Educação Física e Esportes. Belo Horizonte: Health, 2002. 